Clinical report

\title{
Co-ingestion of amatoxins and isoxazoles-containing mushrooms and successful treatment: A case report
}

\author{
Juliana Garcia a, *, Vera M. Costa a , Ana Elisa Costa ${ }^{b}$, Sérgio Andrade ${ }^{c}$, \\ Ana Cristina Carneiro ${ }^{c}$, Filipe Conceição ${ }^{c}$, José Artur Paiva ${ }^{b}$, Paula Guedes de Pinho ${ }^{a}$, \\ Paula Baptista ${ }^{\mathrm{d}}$, Maria de Lourdes Bastos ${ }^{\mathrm{a}}$, Félix Carvalho ${ }^{\mathrm{a},{ }^{,} \text {* }}$ \\ ${ }^{\text {a }}$ UCIBIO-REQUIMTE/Laboratory of Toxicology, Department of Biological Sciences, Faculty of Pharmacy, University of Porto, Rua José Viterbo Ferreira ${ }^{\circ} 228$, \\ 4050-313 Porto, Portugal \\ b Internal Medicine Service, São João Hospital Center, 4200-319 Porto, Portugal \\ ${ }^{c}$ Intermediate Care Unit of Emergency Service, São João Hospital Center, 4200-319 Porto, Portugal \\ ${ }^{\mathrm{d}}$ CIMO/School of Agriculture, Polytechnic Institute of Bragança, Campus de Santa Apolónia, Apartado 1172, $5301-854$ Bragança, Portugal
}

\section{A R T I C L E I N F O}

\section{Article history:}

Received 10 March 2015

Received in revised form 29 May 2015

Accepted 8 June 2015

Available online 16 June 2015

\section{Keywords:}

Wild mushrooms

Amanita pantherina

Amanita phalloides

Isoxazoles

Amatoxins

Intoxication

\begin{abstract}
A B S T R A C T
Mushroom poisonings occur when ingestion of wild mushrooms containing toxins takes place, placing the consumers at life-threatening risk. In the present case report, an unusual multiple poisoning with isoxazoles- and amatoxins-containing mushrooms in a context of altered mental state and poorly controlled hypertension is presented. A 68-year-old female was presented to São João hospital (Portugal) with complaints of extreme dizziness, hallucinations, vertigo and imbalance, $3 \mathrm{~h}$ after consuming a stew of wild mushrooms. The first observations revealed altered mental state and elevated blood pressure. The examination of cooked mushroom fragments allowed a preliminary identification of Amanita pantherina. Gas chromatography-mass spectrometry (GC-MS) showed the presence of muscimol in urine. Moreover, through high-performance liquid chromatography-ultraviolet detection (HPLC-UV) analysis of the gastric juice, the presence of $\alpha$-amanitin was found, showing that amatoxins-containing mushrooms were also included in the stew. After 4 days of supportive treatment, activated charcoal, silybin and Nacetylcysteine, the patient recovered being discharged 10 days post-ingestion with no organ complications. The prompt and appropriate therapy protocol for life-threatening amatoxins toxicity probably saved the patient's life as oral absorption was decreased and also supportive care was immediately started.
\end{abstract}

(ㄷ) 2015 Elsevier Ltd. All rights reserved.

\section{Introduction}

An altered mental state is a very common occurrence in the emergency room and the diagnosis/treatment is highly challenging (Xiao et al., 2012). In fact, two or more etiologies may coexist, including pathological disorders, (e.g. hypoglycemia; cranial

Abbreviations: CNS, central nervous system; DAD, diode-array; EC, electrochemical coulometric detection; DNA, deoxyribonucleic acid; GC-MS, gas chromatography-mass spectrometry; HPLC, high performance liquid chromatography; RNA, ribonucleic acid; RNAP II, RNA polymerase II; TIC, total ion chromatogram; UV ultraviolet.

* Corresponding authors.

E-mail addresses: jugarcia_18@hotmail.com (J. Garcia), felixdc@ff.up.pt (F. Carvalho). trauma; alcohol; infection; psychoses; stroke; hypertensive, metabolic, hepatic, or uremic encephalopathies), consumption of psycho-active substances; and others (Schwartz et al., 1992). Among these, possible accidental or intentional exposure to psycho-active substances present in some wild mushroom species should not be neglected (Tsujikawa et al., 2006). In fact, consumption of wild mushrooms has increased substantially in the last decades (Thimmel and Kluthe, 1998). Mushrooms are appreciated worldwide as a delicacy, due to their exquisite palatability and texture. Moreover, their chemical, nutritional, and functional properties make them exceptional in the human diet (Cheung, 2010). The ingestion of wild mushrooms-containing toxins frequently occurs, which can put the consumers at life-threatening risk. Mushroom poisoning is usually accidental, rarely suicidal, and frequently occurs as a result of misidentification of a toxic 
mushroom as an edible species (Barbato, 1993; Cochran, 1987). The severity of mushroom poisoning depends on the species of mushroom, the amount of mushroom consumed, the prompt therapy and the health status of the individual (Broussard et al., 2001; Durukan et al., 2007). The main toxins associated to mushroom poisoning are: cyclopeptides, orellanine, gyromitrin, isoxazoles, muscarine, psilocybin and gastrointestinal specific irritants (Koppel, 1993). Of the mentioned toxins, the most dangerous and potentially fatal poisonings are caused by cyclopeptides (mainly amatoxins) (Karlson-Stiber and Persson, 2003), while orellanine, isoxazoles, muscarine, psilocybin, and gyromitrin can cause a serious illness but are rarely fatal (Koppel, 1993). Amatoxins are natural toxic bicyclic octapeptides present in mushroom species from three different genera: Amanita, Galerina, and Lepiota (Vetter, 1998). The species Amanita phalloides is involved in the majority of human fatal cases of mushroom poisoning (Karlson-Stiber and Persson, 2003). Its main toxin is $\alpha$-amanitin, which causes hepatic and kidney damage, often fatal (Faulstich, 1979; Klein et al., 1989; Santi et al., 2012). The mechanisms of toxicity of $\alpha$-amanitin are complex, but its most known mechanism is the inhibition of RNA polymerase II (RNAP II) (Vetter, 1998).

Muscimol and ibotenic acid belong to the family of toxins known as isoxazoles. Amanita pantherina and Amanita muscaria are the most commonly known isoxazoles-containing mushrooms (Diaz, 2005). Data on the incidence of intoxication by isoxazolescontaining mushrooms are scarce. The severity of the symptoms is mild, thus intoxicated people often do not seek medical attention. In Portugal, very few cases of isoxazoles-containing mushrooms intoxications have been reported (Morgado et al., 2006). The American Association of Poison Control Centers annual report of 2012 presented 36 cases of isoxazoles-containing mushroom intoxications in the United States of America, with no related deaths (Mowry et al., 2013). Ibotenic acid is an agonist of glutamic acid receptors; its decarboxylated derivative, muscimol, is an agonist of gamma-aminobutyric acid (GABA) receptors. The central effects of these toxins are generally attributed to the previously mentioned pharmacological properties (Krogsgaard-Larsen et al., 1980; Michelot and Melendez-Howell, 2003; Snodgrass, 1978) and include hallucinations, confusion, dizziness, visual and auditory aesthesia (hypersensitivity), space distortion, and unawareness of time (Michelot and Melendez-Howell, 2003).

In this work, we describe a case of a 68 -years-old patient with poorly controlled hypertension and altered mental state after eating wild mushrooms, and the respective clinical management of the patient. The suspicion of a hypertensive crisis and isoxazolesand amatoxins-containing mushrooms poisoning were taken into consideration in the medical decisions.

\section{Case report}

A 68-years-old female with hypertension was admitted to the emergency room of São João Hospital (Porto, Portugal) after ingestion of mushrooms. After specific query, her son reported that the patient ingested several wild mushrooms that were collected in a public yard by the patient. She stewed the mushrooms, and, immediately after ingestion, she started experiencing dizziness, vertigo and imbalance. She self-induced vomiting and had no symptoms of nausea, spontaneous vomiting or diarrhea. On admission, $3 \mathrm{~h}$ post-ingestion, the examination revealed an altered mental status including confusion and repetitive speech, only responsive to severe painful stimuli, and mydriatic pupils. These symptoms resolved in a few hours after admission. Initial emergency room vital signs were: blood pressure 230/108 $\mathrm{mmHg}$, normal pulse and respiratory rate, temperature $96.8^{\circ} \mathrm{F}$, and oxygen saturation of 97.5 percent using an oxygen mask at $10 \mathrm{~L} / \mathrm{min}$.
Physical examination demonstrated dry skin and dry mucous membranes. Additionally, she had clear breath and heart sounds, no abdominal tenderness, and no gross focal neurologic deficits. A brain computed tomography was immediately performed revealing no abnormalities. Additionally, electrocardiogram, funduscopy and urinary sediment were analyzed demonstrating no evidence of lesions. Her serial hematological parameters, coagulation profile, liver and renal function tests were normal.

As a standard procedure for intoxications with wild mushrooms and until species identification by the laboratory, the general detoxification treatment with oral-activated charcoal was immediately instituted on admission, and followed the specific treatment for A. phalloides poisoning, through the administration of silybin and $\mathrm{N}$-acetylcysteine. $\mathrm{N}$-acetylcysteine and silybin were administered in a loading dose of $10.5 \mathrm{~g}(150 \mathrm{mg} / \mathrm{kg})$ and $350 \mathrm{mg}(5 \mathrm{mg} / \mathrm{kg})$, respectively, followed by perfusion. The perfusion of silybin was maintained at a dosage of $58 \mathrm{mg} / \mathrm{h}(20 \mathrm{mg} / \mathrm{kg} / \mathrm{d})$ and N-acetylcysteine at $875 \mathrm{mg} / \mathrm{h}(12.5 \mathrm{mg} / \mathrm{kg} / \mathrm{h})$ for the following $4 \mathrm{~h}$. Labetalol perfusion was also administered for blood pressure control. The patient was then transferred to the intermediate care unit to continue with the treatment with continuous surveillance. A total of $300 \mathrm{mg} / \mathrm{kg}$ of $\mathrm{N}$-acetylcysteine was administered in the first $21 \mathrm{~h}$ after admission. The perfusion of activated charcoal and silybin was kept until the fourth day (at the fourth day, normal coagulation profile and liver function tests were observed). Serum aminotransferases and coagulation profile were normal during all the time that the patient remained admitted, although an elevation of total bilirubin (twofold the normal value) was observed at day 2 (conjugated bilirubin was normal at that time). Two days, total bilirubin level started to decline, and it normalized within one week. After labetalol perfusion, the blood pressure control was achieved by administration of sublingual captopril until the fourth day.

The patient kept some of the stew's leftovers, which were then provided for analysis. The identification of the mushrooms was firstly performed by 2 experts based on the macroscopic features of the fruiting body (Courtecuisse, 1999; Courtecuisse and Duhem, 2005). In the stewed mushrooms, the color of some of the cap fragments resembled $A$. pantherina, namely brown with whitishbrown warts (Fig. 1). The gills were free and whitish-brown color and the stipe was cylindrical and seemed to be white. Therefore, to confirm the intoxication by $A$. pantherina, we looked for the

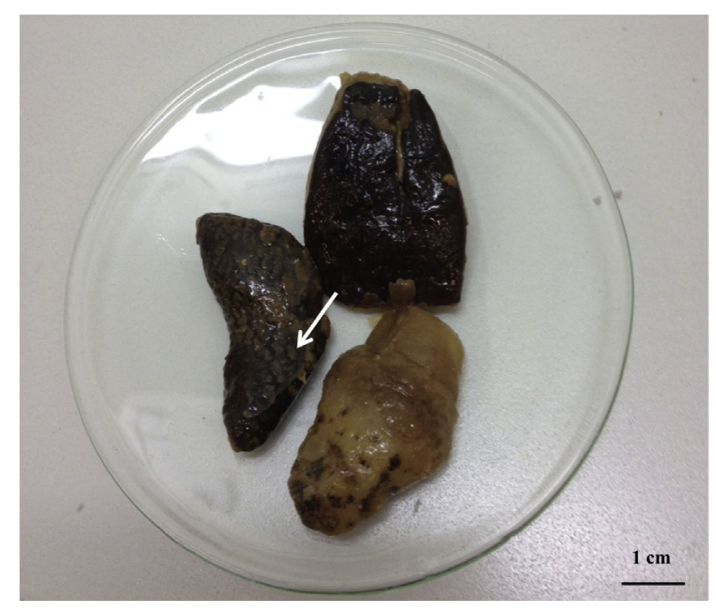

Fig. 1. Macroscopic identification of Amanita pantherina found in the stew, showing its characteristic features in a mushroom fragment (left). The cap fragments are brown with whitish-brown warts (white arrow). (For interpretation of the references to color in this figure legend, the reader is referred to the web version of this article.) 
presence of muscimol in the patient's urine according to the method of derivatization with N-methyl-N-(trimethylsilyl)trifluoroacetamide (MSTFA) reported in Carvalho et al. 2014. Gas chromatography-mass spectrometry (GC-MS) analysis confirmed the presence of muscimol (Fig. 2) in the patient's urine. The data allowed to identify the putative responsible for the patient's hallucinogenic effects, since she possibly ingested ibotenic acid and muscimol-containing mushrooms. Since the possibility of an A. phalloides intoxication is extremely severe, the presence of the main toxin of this mushroom was investigated in the biological fluids (urine and gastric juice) and in the mushrooms collected. $\alpha$ Amanitin was identified in the gastric fluid by high-performance liquid chromatography with ultraviolet detection (Fig. 3), as previously described (Garcia et al., 2014). The $\alpha$-amanitin levels in the gastric fluid were $1.12 \mu \mathrm{g} / \mathrm{mL}$, whereas no detectable levels of $\alpha$ amanitin were found in the urine [the method limit of detection is $0.05 \mu \mathrm{g} / \mathrm{mL}$ (Garcia et al., 2014)].

In the fifth day after mushroom ingestion, the patient was discharged from the intermediate care and transferred to the ward

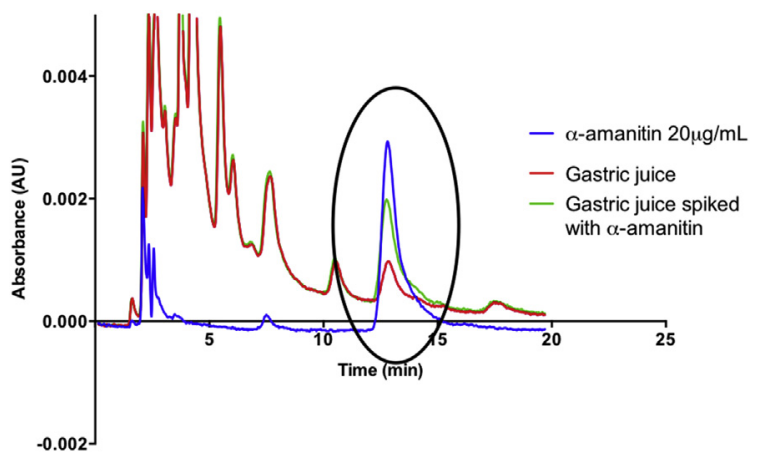

Fig. 3. Chromatogram of the patient's gastric juice recorded at $305 \mathrm{~nm}$ superposed to the chromatograms of the same sample spiked with $\alpha$-amanitin and standard solution of $20 \mu \mathrm{g} / \mathrm{mL}$ of $\alpha$-amanitin.
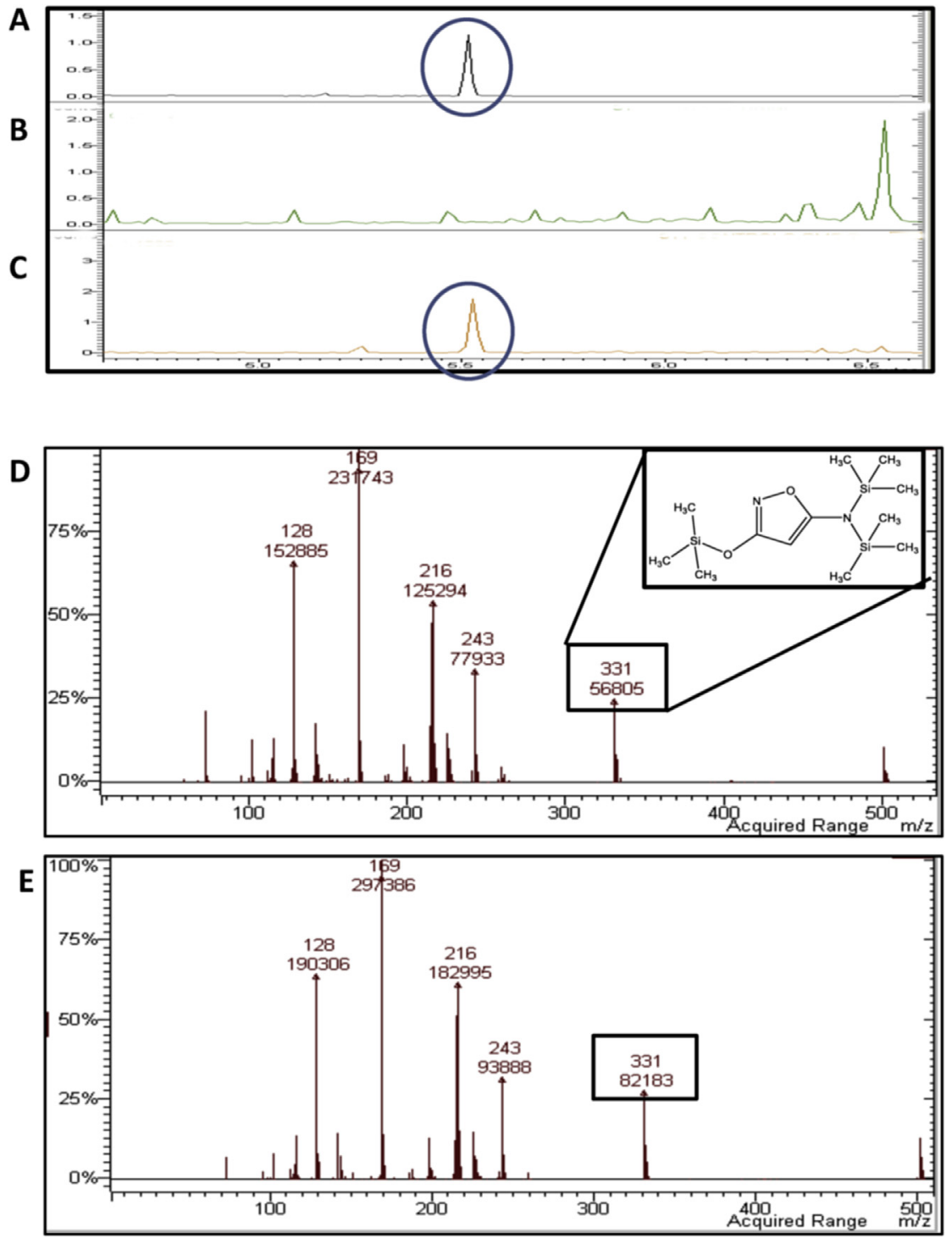

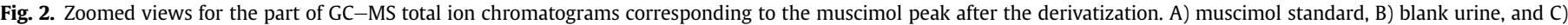

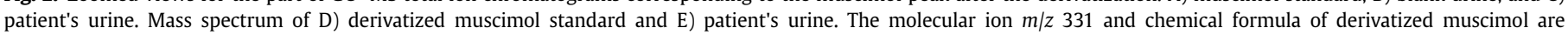
represented. 
without any evidence of liver abnormalities and with better blood pressure control. Ten days post-ingestion the patient was discharged home with no organ complications.

\section{Discussion}

Altered mental status comprises clinical symptoms including cognitive disorders, attention disorders, arousal disorders, and decreased level of consciousness (Xiao et al., 2012). It is a very common situation in the emergency room, and it has many possible causes, including pathological disorders and as a result of consumption of psycho-actives substances (Xiao et al., 2012). In the case presented herein, the high blood pressure in association with altered mental status lead to suspicion of a hypertensive crisis case. However, the clinical evaluation showed no lesion in target organs (normal brain computed tomography, electrocardiogram, funduscopy and urinary sediment), thus that hypothesis was discarded. At the same time, the history of wild mushroom consumption resulted in clinical preventive measures to counteract its putative life-threatening toxicity. Worldwide, most cases of intoxications by wild mushrooms have been attributed to amatoxin-containing mushrooms (Brandão et al., 2011; Mowry et al., 2013), with only a very small percentage of cases attributed to ibotenic acid and muscimol-containing mushrooms (Morgado et al., 2006; Mowry et al., 2013).

In the case presented herein, the features of the clinical presentation are consistent with the diagnosis of intoxication by isoxazoles-containing mushrooms. Positive identification of A. pantherina mushroom, found in the patient's home, was accomplished by 2 experts. This species contains the toxins ibotenic acid and muscimol (Michelot and Melendez-Howell, 2003). Ibotenic acid is metabolized to muscimol (Michelot and MelendezHowell, 2003) and the presence of muscimol was confirmed in the patient's urine sample. Muscimol and ibotenic acid cross the blood-brain barrier exerting their effects primarily on the Central Nervous System (CNS), where they act as neurotransmitter agonists (Michelot and Melendez-Howell, 2003). Ibotenic acid mimics the excitatory amino acid glutamic acid and acts on N-methyl-Daspartic acid (NMDA) receptors. Muscimol is a potent agonist of $\mathrm{GABA}_{\mathrm{A}}$ receptors and also exerts CNS effects (Michelot and Melendez-Howell, 2003). Nausea, hallucinations, delirium, and sleepiness are often described after isoxazoles-containing mushrooms ingestion (Diaz, 2005; Satora et al., 2006). The toxic threshold estimated for ibotenic acid and muscimol is $30-60 \mathrm{mg}$ and $6 \mathrm{mg}$, respectively (Halpern, 2004) and these amounts can be found in a single mushroom (Rumack and Spoerke, 1994). At this point, the toxicokinetics of either muscimol or ibotenic acid remains largely unknown, but based on the rapid onset of symptoms after mushrooms ingestion, a fast absorption of toxins is presumed. Moreover, the toxins are readily excreted in urine, where they can be detected within $1 \mathrm{~h}$ after ingestion (Stribrny et al., 2012). Clinical symptoms have been reported 30 min to $2 \mathrm{~h}$ after ingestion and include nausea, hallucinations, delirium, muscular spasm, and sleepiness (Diaz, 2005; Satora et al., 2006). The CNS effects are usually short-lived, and fatalities rarely occur (Benjamin, 1992; Diaz, 2005), thus the recommended treatment for isoxazolescontaining mushrooms consists of eliminating the toxins from the gastrointestinal tract, administration of activated charcoal, and supportive measures to alleviate CNS symptoms (Michelot and Melendez-Howell, 2003). Even when the intoxication symptoms largely indicate a self-limited mushroom intoxication, if the patient's meal contained wild mushrooms, the possible presence of amatoxins should not be ruled out and should be taken into consideration in the medical protocol. Amatoxins are a group of toxic bicyclic octapeptides present in the genus Amanita. $\alpha$ -
Amanitin is considered the main responsible for the human toxic effects. Upon ingestion, $\alpha$-amanitin binds to the RNAP II enzyme, inhibits the transcription process and, ultimately, causes cell death. The main target organ seems to be the liver (Letschert et al., 2006) but the kidneys can also be compromised (Amini et al., 2011). In the liver, $\alpha$-amanitin causes broad necrosis that results in acute hepatic failure and further complications, such as hepatic coma, coagulation disorders, renal failure (Enjalbert et al., 2002). The estimated lethal dose of amatoxins in humans is about $0.1 \mathrm{mg} / \mathrm{kg}$ body weight, or even lower, and this lethal amount may be present in a single mushroom (Faulstich, 1980). Upon ingestion, amatoxins seem to be gradually absorbed in the gastrointestinal tract. In the present case, the patient was taken to the hospital emergency room $3 \mathrm{~h}$ after mushrooms ingestion and the presence of $\alpha$-amanitin was confirmed in the gastric juice but not in the urine sample taken. We can presume that the fast CNS symptoms elicited the fast hospital admission, even before the amatoxins were fully absorbed. The gastric lavage was immediately performed in the hospital and decreased or even abrogated the absorption of the toxins. The clinical course after amatoxins intoxication is initially characterized by a latent period followed by gastrointestinal symptoms, which include nausea, diarrhea and vomiting. However, no amatoxins toxicity signs or symptoms are usually found until 6-24 h after ingestion (Enjalbert et al., 2002). Presently, there is currently no specific and effective antidote for $A$. phalloides poisoning but several therapeutic drugs are used to protect the target organs of amatoxins poisoning. Intravenous silybin is the pharmacologic treatment of choice in Europe (Mengs et al., 2012) and in the USA (French et al., 2011). Other therapies have been suggested and include benzylpenicillin, ceftazidime, or $\mathrm{N}$-acetylcysteine (Enjalbert et al., 2002). The administration of silybin in amatoxin poisoning cases is based on its strong antioxidant activity and the ability to stimulate RNA polymerase I, counterbalancing the inhibition of RNAP II activity caused by amatoxins (Fraschini et al., 2002). N-acetylcysteine's potential therapeutic effect is due to its known antioxidant activity (Montanini et al., 1999).

Since $\alpha$-amanitin undergoes extensive enterohepatic recycling, repeated doses of activated charcoal were, also, administered, to enhance its elimination. The administration of activated charcoal had implications in the choice of the administration route of the antihypertensive drug to be used. Activated charcoal may prevent the absorption of orally administered therapeutic agents; therefore sublingual captopril was administered.

In summary, in the present case, the treatment of a patient that suffered mushroom intoxication was immediately started after patient's admission and consisted of gastric lavage, oral-activated charcoal, silybin and $\mathrm{N}$-acetylcysteine, and antihypertensive therapy. It can be inferred that the early hospitalization, rapid diagnosis and aggressive management concurred for the successful outcome after $A$. phalloides lethal mushroom poisoning. Every effort should be made to identify the toxins present in the mushrooms ingested as to continue with supportive therapy or not, but clinical measures should not wait for the analytical results, as time is of the essence in these cases. In the present situation, the simultaneous ingestion of isoxazoles toxins and amatoxins lead to the early application of the A. phalloides therapy protocol in hospital settings, since the former caused rapid hallucinogenic symptoms. The facilities for toxicological analysis are not commonly available in most hospitals. The collaboration between hospitals and toxicological laboratories and the communication between physicians and toxicologists could be helpful in reducing the time of therapy implemented, as well as the morbidity and mortality in cases of poisoning. The rapid hospitalization and the history of mushrooms ingestion led to an early therapeutic intervention in an amatoxins poisoning, which was key to prevent complications resulting from amatoxins intoxication. 


\section{Ethical statement}

The authors declare that this manuscript complies with the Elsevier Ethical Guidelines for Journal Publication.

\section{Acknowledgments}

This work received financial support from the European Union (FEDER funds through COMPETE) and National Funds (FCT, Fundação para a Ciência e Tecnologia) through project Pest-C/EQB/ LA0006/2013.

Juliana Garcia and Vera Marisa Costa thank FCT - Foundation for Science and Technology - for their PhD grant (SFRH/BD/74979/ 2010) and Post-doc grant (SFRH/BPD/63746/2009), respectively.

\section{Transparency document}

Transparency document related to this article can be found online at http://dx.doi.org/10.1016/j.toxicon.2015.06.012.

\section{References}

Amini, M., Ahmadabadi, A., Kazemifar, A.M., Solhi, H., Jand, Y., 2011. Amanita Phalloides intoxication misdiagnosed as acute appendicitis: a case report. Iran. Toxicol. 5, 527-530.

Barbato, M.P., 1993. Poisoning from accidental ingestion of mushrooms. Med. J. Aust. $158,842-847$.

Benjamin, D.R., 1992. Mushroom poisoning in infants and children: the Amanitc pantherina/Muscaria group. Clin. Toxicol. 30, 13-22.

Brandão, J.L., Pinheiro, J., Pinho, D., Correia da Silva, D., Fernandes, E., Fragoso, G. Costa, M.I., Silva, A., 2011. Intoxicação por cogumelos em portugal. Acta Med. Port. 24, 269-278.

Broussard, C.N., Aggarwal, A., Lacey, S.R., Post, A.B., Gramlich, T., Henderson, J.M., Younossi, Z.M., 2001. Mushroom poisoning - from diarrhea to liver transplantation. Am. J. Gastroenterol. 96, 3195-3198.

Carvalho, L.M., Carvalho, F., de Lourdes Bastos, M., Baptista, P., Moreira, N., Monforte, A.R., da Silva Ferreira, A.C., de Pinho, P.G., 2014. Non-targeted and targeted analysis of wild toxic and edible mushrooms using gas chromatography-ion trap mass spectrometry. Talanta 118, 292-303.

Cheung, P.C.K., 2010. The nutritional and health benefits of mushrooms. Nutr. Bull. $35,292-299$.

Cochran, K., 1987. Poisonings due to misidentified mushrooms. Mcllvainea 8, 27-29.

Courtecuisse, R., 1999. Mushrooms of Britain and Europe. HarperCollins Publ., London.

Courtecuisse, R., Duhem, B., 2005. In: Omeda, E. (Ed.), Guía de los hongos de la Peninsula Ibérica, Europa y Norte de África. Barcelona.

Diaz, J.H., 2005. Syndromic diagnosis and management of confirmed mushroom poisonings. Crit. Care Med. 33, 427-436.

Durukan, P., Yildiz, M., Cevik, Y., Ikizceli, I., Kavalci, C., Celebi, S., 2007. Poisoning from wild mushrooms in Eastern Anatolia region: analyses of 5 years. Hum. Exp. Toxicol. 26, 579-582.

Enjalbert, F., Rapior, S., Nouguier-Soule, J., Guillon, S., Amouroux, N., Cabot, C., 2002 Treatment of amatoxin poisoning: 20-year retrospective analysis. J. Toxicol. Clin. Toxicol. 40, 715-757.

Faulstich, H., 1979. New aspects of Amanita poisoning. Klin. Wochenschr. 57, $1143-1152$
Faulstich, H., 1980. Mushroom poisoning. Lancet 316, 794-795.

Fraschini, F., Demartini, G., Esposti, D., 2002. Pharmacology of silymarin. Clin. Drug Investig. 22, 51-65.

French, L.K., Hendrickson, R.G., Horowitz, B.Z., 2011. Amanita phalloides poisoning. Clin. Toxicol. 49, 128-129.

Garcia, J., Costa, V.M., Baptista, P., Bastos, M.L., Carvalho, F., 2014. Quantification of alpha-amanitin in biological samples by HPLC using simultaneous UV-diode array and electrochemical detection. J. Chromatogr. B. http://dx.doi.org/ 10.1016/j.jchromb.2015.06.001. Submitted.

Halpern, J.H., 2004. Hallucinogens and dissociative agents naturally growing in the United States. Pharmacol. Ther. 102, 131-138.

Karlson-Stiber, C., Persson, H., 2003. Cytotoxic fungi-an overview. Toxicon 42, 339-349.

Klein, A.S., Hart, J., Brems, J.J., Goldstein, L., Lewin, K., Busuttil, R.W., 1989. Amanita poisoning: treatment and the role of liver transplantation. Am. J. Med. 86, 187-193.

Koppel, C., 1993. Clinical symptomatology and management of mushroom poisoning. Toxicon 31, 1513-1540.

Krogsgaard-Larsen, P., Honore, T., Hansen, J.J., Curtis, D.R., Lodge, D., 1980. New class of glutamate agonist structurally related to ibotenic acid. Nature 284, 64-66.

Letschert, K., Faulstich, H., Keller, D., Keppler, D., 2006. Molecular characterization and inhibition of amanitin uptake into human hepatocytes. Toxicol. Sci. 91, $140-149$.

Mengs, U., Pohl, R.T., Mitchell, T., 2012. Legalon(R) SIL: the antidote of choice in patients with acute hepatotoxicity from amatoxin poisoning. Curr. Pharm. Biotechnol. 13, 1964-1970.

Michelot, D., Melendez-Howell, L.M., 2003. Amanita muscaria: chemistry, biology, toxicology, and ethnomycology. Mycol. Res. 107, 131-146.

Montanini, S., Sinardi, D., Pratico, C., Sinardi, A.U., Trimarchi, G., 1999. Use of acetylcysteine as the life-saving antidote in Amanita phalloides (death cap) poisoning. Case report on 11 patients. Arzneimittelforschung 49, 1044-1047.

Morgado, L., Martins, L., Gonçalves, H., Oliveira, P., 2006. Estudo de intoxicações causadas por ingestão de macrofungos na região do Alto Alentejo. Anais da Associação Micológica A Pantorra 6, 65-74.

Mowry, J.B., Spyker, D.A., Cantilena Jr., L.R., Bailey, J.E., Ford, M., 2013. 2012 annual report of the american association of poison control centers' national poison data system (NPDS): 30th annual report. Clin. Toxicol. 51, 949-1229.

Rumack, B.H., Spoerke, D.G., 1994. Handbook of mushroom poisoning: diagnosis and treatment. Taylor \& Francis.

Santi, L., Maggioli, C., Mastroroberto, M., Tufoni, M., Napoli, L., Caraceni, P., 2012. Acute liver failure caused by Amanita phalloides poisoning. Int. J. Hepatol. 2012,

Satora, L., Pach, D., Ciszowski, K., Winnik, L., 2006. Panther cap Amanita pantherina poisoning case report and review. Toxicon 47, 605-607.

Schwartz, R.B., Jones, K.M., Kalina, P., Bajakian, R.L., Mantello, M.T., Garada, B., Holman, B.L., 1992. Hypertensive encephalopathy: findings on CT, MR imaging, and SPECT imaging in 14 cases. Am. J. Roentgenol. 159, 379-383.

Snodgrass, S.R., 1978. Use of $3 \mathrm{H}$-muscimol for GABA receptor studies. Nature 273 392-394.

Stribrny, J., Sokol, M., Merova, B., Ondra, P., 2012. GC/MS determination of ibotenic acid and muscimol in the urine of patients intoxicated with Amanita pantherina. Int. J. Leg. Med. 126, 519-524.

Thimmel, R., Kluthe, R., 1998. The nutritional database for edible mushrooms. Ernahrung 22, 63-65.

Tsujikawa, K. Mohri, H., Kuwayama, K., Miyaguchi, H., Iwata, Y., Gohda, A, Fukushima, S., Inoue, H., Kishi, T., 2006. Analysis of hallucinogenic constituents in Amanita mushrooms circulated in Japan. Forensic Sci. Int. 164, 172-178.

Vetter, J., 1998. Toxins of Amanita phalloides. Toxicon 36, 13-24.

Xiao, H., Wang, Y, Xu, T, Zhu, H., Guo, S., Wang Z, Yu, X, 2012. Evaluation and treatment of altered mental status patients in the emergency department: life in the fast lane. World J. Emerg. Med. 3, 270-277. 